\title{
In Pursuit of an Ideal - A Perspective on Non-Invasive Continuous Glucose Monitoring
}

\author{
Lisa B English
}

Director of Scientific and Technological Affairs, c8 Medisensors

\begin{abstract}
Diabetes is one of the most common non-communicable diseases globally, and is the fourth or fifth leading cause of death in many countries. Medical technology for the management of diabetes has advanced steadily since the discovery of insulin in the early 20 th century. Today, individuals with diabetes benefit from home-use blood glucose meters, continuous insulin pumps and, most recently, continuous glucose monitoring (CGM). Numerous studies have shown that frequent use of real-time CGM can improve glycaemic control with reduced risk of hypoglycaemia. However, current CGM devices have not been wholeheartedly embraced, limiting their potential. A CGM device that is accurate, non-invasive, pain-free and non-intrusive to daily activities could drive increased adoption and use of CGM, potentially improving health and quality of life for many individuals living with diabetes.
\end{abstract}

\section{Keywords}

Diabetes, continuous glucose monitoring, non-invasive continuous glucose monitoring, real-time continuous glucose monitoring, $\mathrm{HbA}_{1 \mathrm{C}}$, tight glycaemic control, ideal glucose monitor

Disclosure: Lisa B English is an employee of C8 MediSensors.

Received: 15 December 2011 Accepted: 19 January 2012 Citation: European Endocrinology, 2012; 8(1):18-21. DOl:10.17925/EE.2012.08.01.18 Correspondence: Lisa B English, C8 MediSensors, 6375 San Ignacio Avenue, San Jose, California 95119, US. E: Ienglish@c8medisensors.com

Support: The publication of this article was funded by C8 Medisensors.

Approximately 366 million individuals worldwide have type 1 or type 2 diabetes, and it is likely that global prevalence will rise to 552 million individuals by $2030 .{ }^{1}$ Currently, an estimated 4.6 million deaths are attributed to diabetes annually. ${ }^{1}$ Undisputedly, the best way to address this 'diabetes epidemic' is through a global commitment to prevention, early diagnosis, accurate monitoring and effective treatment.

\section{Criticality of Tight Glycaemic Control}

The comprehensive, 10-year Diabetes Control and Complications Trial (DCCT) in 1993, which established glycated haemoglobin $\left(\mathrm{HbA}_{1 \mathrm{c}}\right)$ as a gold standard measure of long-term glycaemic control, clearly demonstrated that individuals with type 1 diabetes who kept blood glucose levels as close to normal as possible for as long as possible had less chance of developing disease-related complications. ${ }^{2-4}$ Since that time, other studies have confirmed the importance of tight glycaemic control with minimal glucose excursions in reducing disease-related complications not only in type 1 diabetes, but also in type 2 diabetes..$^{5-9}$ Today, individuals with diabetes are encouraged to maintain blood glucose at normal or nearnormal levels. Furthermore, those who take insulin injections are encouraged to follow intensive treatment programmes with tight glycaemic control targets, which require frequent glucose monitoring. ${ }^{10}$

\section{Barriers to Tight Glycaemic Control}

Despite advances in technologies and therapeutics, intensive treatment of type 1 diabetes frequently fails to achieve target $\mathrm{HbA}_{1 c}$ as recommended by the DCCT more than 15 years ago. ${ }^{11}$ Many individuals - including those who measure blood glucose several times daily - still experience postprandial hyperglycaemia and asymptomatic nocturnal hypoglycaemia. ${ }^{12,13}$ These findings suggest that tight glycaemic control is difficult to achieve for many individuals with diabetes. There are a variety of reasons for this, including fear of hypoglycaemia, poor adherence to self-monitoring of blood glucose (SMBG) and lack of continuous data about glucose dynamics.

\section{Hypoglycaemia}

Hypoglycaemia can lead to neurologic, cognitive and cardiovascular dysfunctions, and if left untreated, death. ${ }^{13}$ Frequent hypoglycaemic episodes can cause 'hypoglycaemia unawareness', a condition that leaves an individual unable to recognise hypoglycaemia when it occurs. As the most feared complication of insulin therapy, ${ }^{14,15}$ hypoglycaemia is the main reason why individuals with diabetes who take insulin injections are hesitant to pursue intensive blood glucose control."

\section{Insufficient Monitoring}

Despite ever-increasing evidence that tight glycaemic control reduces risk of disease-related complications, many individuals with diabetes do not monitor glucose often enough to achieve this objective. ${ }^{16-19}$ One study showed that only $40 \%$ of those with type 1 diabetes and $26 \%$ of those with type 2 diabetes performed SMBG at least once a day, ${ }^{20}$ and several other studies have demonstrated low SMBG adherence. ${ }^{21-23}$ The reasons are numerous, but often include cost, pain, inconvenience and complexity of testing requirements. ${ }^{18,21,24-26}$

\section{Incomplete Data}

The rate of formation of $\mathrm{HbA}_{1 \mathrm{c}}$ is directly proportional to the ambient glucose concentration. Since erythrocytes are freely permeable 
to glucose, the level of $\mathrm{HbA}_{1 \mathrm{C}}$ in a blood sample provides a glycaemic history of the previous 120 days, the average lifespan of an erythrocyte. The test, however, provides no information about glycaemic excursions. So, an individual could have numerous excursions that, in essence, cancel each other out to deliver an acceptable $\mathrm{HbA}_{1 \mathrm{c}}$ value. Such a situation would put that individual at risk of developing diabetes-related complication..$^{2-5,11}$ Even SMBG provides only a spot measurement of an individual's glucose level, with no information about rate or direction of change. Unless performed every 15-30 minutes, which is impractical given requirements for finger-stick blood samples and cost of test strips, SMBG simply cannot provide enough information about direction, magnitude, duration, frequency and cause of glucose fluctuations to provide a complete picture of glucose dynamics over time. Without complete information about time spent hyper-, hypo- and euglycaemic, it is difficult for an individual to achieve tight glycaemic control.

\section{Overcoming Barriers - Continuous Glucose Monitoring \\ Improved Glycaemic Control}

Real-time CGM (RT-CGM) became available around 2006. It provides a complete picture of glucose levels over time and in the context of daily activities. Since then, a large number of studies have shown that RT-CGM can improve glycaemic control with reduced risk of hypoglycaemia. ${ }^{27-39}$ A recent review of 19 randomised controlled trials (RCTS) concluded that RT-CGM lowered $\mathrm{HbA}_{1 \mathrm{C}}$ in adults with type 1 diabetes..$^{40}$ In addition, of nine RCTs focused on the use of RT-CGM data verified by SMBG data to make dynamic therapeutic adjustments for people with diabetes, ${ }^{32,41-45}$ seven demonstrated benefit. Four showed improved glycaemic excursions, reduced glycaemic variability, decreased time spent in hypo- and hyperglycaemia, and improved $\mathrm{HbA}_{1 \mathrm{c}}$ with $\mathrm{RT}-\mathrm{CGM}_{1}^{; 1,43-45}$ one reached similar conclusions but did not evaluate $\mathrm{HbA}_{1 \mathrm{C}^{-32}}$ and two showed improved $\mathrm{HbA}_{1 \mathrm{C}}$ with frequent use of RT-CGM. ${ }^{27,46}$ Although the three remaining studies did not find a significant benefit of RT-CGM on metabolic control, one noted decreased use of CGM due to skin irritation $^{42}$ and the other two involved less than daily use of CGM, ${ }^{47,48}$ which could have affected results. Finally, several studies have observed that RT-CGM can improve glycaemic control when used as part of an insulin pump regimen if used at least $70 \%$ of the time. ${ }^{8.49,50}$

Furthermore, the benefit of RT-CGM extends to type 2 diabetes. A recent review of published studies concluded that RT-CGM can improve glycaemic control in individuals with type 2 diabetes ${ }^{51}$ And, two RCTs of CGM in type 2 diabetes drew similar conclusions, ${ }^{52,53}$ suggesting that RT-CGM might benefit a wider range of individuals with diabetes than previously thought. Other studies have shown CGM to be useful for modifying diet and exercise to improve glycaemic contro| ${ }^{11,54}$ and reduce risk factors for diabetes-related complications. ${ }^{51,55,56}$ Real-time CGM has also been used to detect postprandial hyperglycaemia ${ }^{12,57}$ and determine postprandial glycaemic profiles following ingestion of meals of different composition. ${ }^{58}$ This is of particular benefit given the prominent role that postprandial hyperglycaemia can play in the development of vascular complications of diabetes. ${ }^{59}$

\section{Limited Adoption and Use}

Despite the benefit of RT-CGM, it has not been wholeheartedly embraced for reasons such as complexity, inappropriate expectations, invasiveness, cost, pain, discomfort, risk of infection and the degree to which it is perceived to interfere with daily life. ${ }^{60}$ These issues have limited willingness to begin CGM as well as frequency of CGM use once started. Since clinical studies have shown a linear relationship between increased use of CGM and lowered $\mathrm{HbA}_{1 \mathrm{C}}{ }^{29,61}$ lack of adoption and infrequent use are serious concerns. All current CGM devices are invasive, requiring insertion of a needle catheter into the subcutaneous adipose tissue to measure glucose in the interstitial fluid. The insertion injures the local microvasculature, extracellular matrix of structural proteins and adipose cells, and the wound fills with red blood cells, platelets, coagulation proteins and cellular debris which can compromise sensor performance. ${ }^{62-64}$ Both the warm-up period required for sensor stability and sensor performance depend to a large degree on the extent of tissue injury, with more extensive injury requiring more frequent sensor recalibration to ensureaccuracy. ${ }^{62}$ Sensor insertion and implantation can also result in pain or discomfort, and can pose a risk of infection.

In addition, current CGM devices require calibration against blood glucose values as often as twice a day. As a result, the cost associated with current CGM devices can be high, including the CGM device and sensors as well as consumables for SMBG calibration of the device. Similarly, overall accuracy of current CGM is subject not only to the accuracy of the CGM device, but also the accuracy of the SMBG device used to calibrate it as well as the ability of the individual to use both devices proficiently. ${ }^{65}$ Of note is the fact that blood glucose meters are calibrated based on a laboratory reference, but current CGM devices are calibrated against a blood glucose meter, putting them one step away from calibration against a laboratory reference. So, despite the tremendous technological advance that current CGM devices represent, they are not ideal glucose monitoring solutions, which begs the question: what is an ideal solution?

\section{Toward an Ideal - Non-Invasive Continuous Glucose Monitoring}

When asked about the characteristics of an ideal glucose monitor, healthcare professionals and individuals with diabetes often start by stating the device must be non-invasive, non-intrusive and pain-free. It would, of course, accurately monitor glucose levels continuously, warn of impending glycaemic excursions and be small enough to be worn discreetly. So, how would those characteristics translate into a new medical device?

\section{Accuracy to Support Tight Glycaemic Control Targets}

It goes without saying that an ideal glucose monitor must be accurate. The question is: how accurate? Current CGM devices have mean absolute relative differences (MARD) around $13-25 \%,{ }^{66-70}$ and a recent study of seven SMBG devices reported MARDS ranging from $6.5-12 \%{ }^{71} \mathrm{~A}$ non-invasive monitor with a MARD towards the low end or below current CGM devices would certainly offer improvement, and one that approached the MARD of SMBG devices would be closer to ideal. Further, a CGM device that required no user calibration would eliminate one common source of inaccuracy.

\section{Continuous Information to Drive Optimal Lifestyle, Diet and Treatment}

The value of RT-CGM is clear: it provides a complete picture of glucose dynamics over time, including all peaks and valleys, enabling 


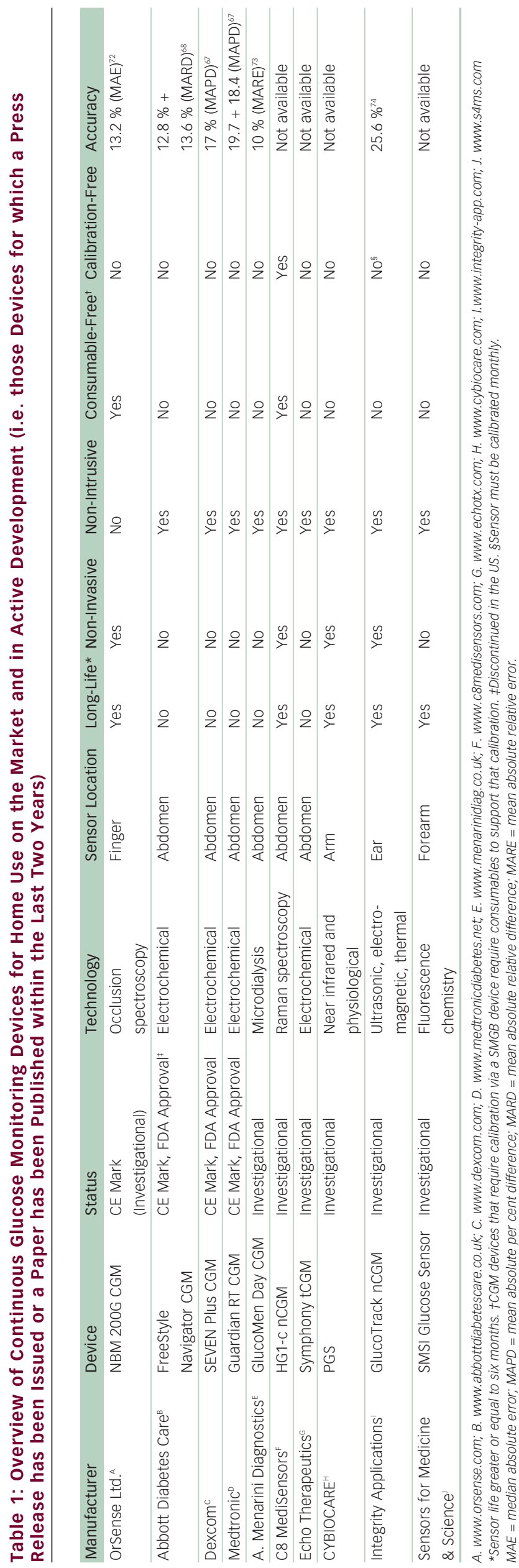

individuals with diabetes and their healthcare teams to maximise euglycaemia. Real-time information can help individuals understand the relationship between lifestyle and dietary choices and their glucose dynamics while retrospective data can help healthcare professionals identify glycaemic patterns and optimise treatment programmes. In addition, real-time monitoring devices can provide customisable alarms that warn of impending hyper- and hypoglycaemia, which will likely ease fear of hypoglycaemia to support implementation of treatment programmes focused on intensive blood glucose control.

\section{Non-invasive and Non-intrusive to Increase Frequency of Use}

To deliver benefit, CGM devices must be used, preferably about $70 \%$ of the time. ${ }^{8.4950}$ A CGM device with a non-invasive, pain-free sensor that does not require frequent replacement would go a long way towards supporting such frequent use. To be truly non-invasive, the monitor must be a non-in vitro diagnostic device - one that does not require a blood, fluid or tissue sample. Obtaining a sample requires disturbing or penetrating the skin barrier, which is unlikely to be painless or non-intrusive. In addition, because truly non-invasive monitoring would not cause injury or trigger a foreign-body response, it would not be subject to the negative impact those events can have on accuracy. ${ }^{62,63}$ Furthermore, many individuals with diabetes have the perception that CGM devices interfere with daily activities. ${ }^{60} \mathrm{~A}$ glucose monitor that could be worn discreetly and be removed when desired without requiring the inconvenience and cost of sensor replacement and recalibration would likely change this perception for the better. In fact, such a device could encourage individuals with diabetes to pursue a wider range of interests since they could keep a close eye on glucose levels throughout most activities.

An ideal glucose monitor, being accurate, continuous, non-invasive and non-intrusive, and having a long-life sensor, would undoubtedly increase the frequency of CGM use and empower individuals to assume more control over their diabetes, improving health and quality of life. Not surprisingly, a number of efforts are underway to develop such a monitor - some closer than others, and some more likely to succeed than others. A larger number of efforts have already come and gone, including the Dream Beam (Futrex Medical Instrumentation Inc.), Diasensor ${ }^{\circledR}$ (BICO Inc.), GlucoWatch ${ }^{\circledR}$ (Cygnus Inc.) and Pendra ${ }^{\circledR}$ (Pendragon Medical Ltd.) CGM devices. Table 1 provides an overview of RT-CGM devices for home use that are actively being developed or already on the market.

\section{Looking Ahead}

Since the discovery of insulin in 1921, medical technology has continued to improve the management of diabetes as well as make life easier for individuals living with the disease. Before 1975, urine monitoring and a fixed dose of insulin once or twice a day was the general standard of care. Since then, medical advances, such as disposable syringes, laboratory glucose tests, continuous insulin pumps, home-use blood glucose meters and, most recently, continuous glucose monitors, have advanced steadily, with each next-generation product delivering added benefit.

It seems likely that the next step in the advancement of medical technologies for diabetes management will be a non-invasive CGM device that meets some, possibly all, of the characteristics identified by healthcare professionals and individuals with diabetes. Such a 
device would support increased adoption and use of CGM, which has been demonstrated repeatedly to reduce risk of long-term diabetes-related complications. .,3,5 $^{2,1 l l}$ a truly non-invasive CGM device be the next technological advance that fundamentally changes the way diabetes is managed, helping individuals living with the disease achieve that elusive goal of tight glycaemic control? Time will tell, but based on current evidence, the answer seems to be: it very likely will.
1. International Diabetes Federation, Diabetes Atlas, 5th Edition, 2011. Available at:

http://www.idf.org/diabetesatlas/news/fifth-edition-release (accessed 12 september 2010)

2. DCCT, The effect of intensive treatment of diabetes on the development and progression of long-term complications in insulin-dependent diabetes mellitus. The Diabetes Control and Complications Trial Research Group, N Engl I Med, 1993;329(14):977-86

3. DCCT, Effect of intensive diabetes treatment on the development and progression of long-term complications in adolescents with insulin-dependent diabetes mellitus: Diabetes Control and Complications Trial. Diabetes Control and Complications Trial Research Group, J Pediatr. 1994:125(2):177-88.

4. DCCT, Lifetime benefits and costs of intensive therapy as practiced in the diabetes control and complications trial. The Diabetes Control and Complications Trial Research Group, JAMA, 1996;276(17):1409-15.

5. UK-PDS, Intensive blood-glucose control with sulphonylureas or insulin compared with conventional treatment and risk of complications in patients with type 2 diabetes (UKPDS 33). UK Prospective Diabetes Study (UKPDS) Group, Lancet, 1998;352(9131):837-53.

6. Monnier L, Colette C, Boegner C, et al., Continuous glucose monitoring in patients with type 2 diabetes: Why? When? Whom? Diabetes Metab, 2007:33(4):247-52.

7. Monnier L, Mas E, Ginet C, et al., Activation of oxidative stress by acute glucose fluctuations compared with sustained chronic hyperglycemia in patients with type 2 diabetes, JAMA, 2006;295(14):1681-7.

8. Hirsch IB, Abelseth J, Bode BW, et al., Sensor-augmented insulin pump therapy: results of the first randomized treat-totarget study, Diabetes Technol Ther, 2008;10(5):377-83.

9. Ceriello $A$, The glucose triad and its role in comprehensive glycaemic control: current status, future management, Int I Clin Pract, 2010;64(12):1705-11.

10. American Diabetes Association, Standards of Medical Care in Diabetes-2011, Diabetes Care, 2011;34(Suppl.1):S11-S61.

11. Thompson CJ, Cummings JF, Chalmers J, et al., How have patients reacted to the implications of the DCCT? Diabetes Care, 1996;19(8):876-9.

12. Boland $\mathrm{E}$, Monsod T, Delucia M, et al., Limitations of conventional methods of self-monitoring of blood glucose: lessons learned from 3 days of continuous glucose sensing in pediatric patients with type 1 diabetes, Diabetes Care, in pediatric patients with: $1858-62$.

13. Wolpert $\mathrm{HA}$, Use of continuous glucose monitoring in the detection and prevention of hypoglycemia, J Diabetes Sci Technol, 2007; 1(1):146-50.

14. Irvine AA, COX D, Gonder-Frederick L, Fear of hypoglycemia relationship to physical and psychological symptoms in patients with insulin-dependent diabetes mellitus, Health Psychol, 1992;11(2):135-8.

15. McCrimmon RJ, Frier BM, Hypoglycaemia, the most feared complication of insulin therapy, Diabete Metab, 1994:20(6):503-12.

16. Harris $\mathrm{MI}$, Frequency of blood glucose monitoring in relation to glycemic control in patients with type 2 diabetes, Diabetes Care, 2001;24(6):979-82.

17. Karter AJ, Ferrara A, Darbinian JA, et al., Self-monitoring of blood glucose: language and financial barriers in a managed care population with diabetes, Diabetes Care, 2000;23(4):477-83.

18. Vincze G, Barner JC, Lopez D, Factors associated with adherence to self-monitoring of blood glucose among persons with diabetes, Diabetes Educ, 2004;30(1):112-25

19. Delamater AM, Improving patient adherence, Clin Diabetes, 2006;24(2):71-7.

20. Harris MI, Cowie CC, Howie $\sqcup$, Self-monitoring of blood glucose by adults with diabetes in the United States population, Diabetes Care, 1993;16(8):1116-23.

21. Goldstein DE, Little RR, Lorenz RA, et al., Tests of glycemia in diabetes, Diabetes Care, 2004;27(7):1761-73.

22. Harris MI, Testing for blood glucose by office-based physicians in the U.S, Diabetes Care, 1990;13(4):419-26.

23. Tuttleman M, Lipsett L, Harris MI, Attitudes and behaviors of primary care physicians regarding tight control of blood glucose in IDDM patients, Diabetes Care, 1993;16(5):765-72.

24. Daviss WB, Coon $\mathrm{H}$, Whitehead $\mathrm{P}$, et al., Predicting diabetic control from competence, adherence, adjustment, and psychopathology, I Am Acad Child Adolesc Psychiatry, 1995;34(12):1629-36

25. Kavanagh DJ, Gooley S, Wilson PH, Prediction of adherence and control in diabetes, J Behav Med, 1993;16(5):509-22.

26. Mazze RS, Lucido D, Shamoon H, Psychological and social correlates of glycemic control, Diabetes Care, 1984;7(4):360-6.

27. Beck RW, Buckingham B, Miller K, et al., Factors predictive of use and of benefit from continuous glucose monitoring in type 1 diabetes, Diabetes Care, 2009;32(11):1947-53.
28. Anderson J, Effect on glycemic control by short- and longterm use of continuous glucose monitoring in clinical practice, J Diabetes Sci Technol, 2011:5(6):1472-8.

29. Bailey TS, Zisser HC, Garg SK, Reduction in hemoglobin A1C with real-time continuous glucose monitoring: results from 12-week observational study, Diabetes Technol Ther 2007:9(3):203-10

30. Chico $A$, Vidal-Ríos $P$, Subirà $M$, Novials $A$, The continuous glucose monitoring system is useful for detecting unrecognized hypoglycemias in patients with type 1 and type 2 diabetes but is not better than frequent capillary glucose measurements for improving metabolic control, Diabetes Care 2003;26(4):1153-7.

31. Garg S, Jovanovic L, Relationship of fasting and hourly blood glucose levels to $\mathrm{HbA}_{1 \mathrm{c}}$ values: safety, accuracy, and improvements in glucose profiles obtained using a 7-day continuous glucose sensor, Diabetes Care, 2006;29(12):2644-9.

32. Garg S, Zisser H, Schwartz S, et al., Improvement in glycemic excursions with a transcutaneous, real-time continuous glucose sensor: a randomized controlled trial, Diabetes Care, 2006;29(1):44-50

33. Kaufman FR, Gibson LC, Halvorson M, et al., A pilot study of the continuous glucose monitoring system: clinical decisions and glycemic control after its use in pediatric type 1 diabetic subjects, Diabetes Care, 2001;24(12):2030-4.

34. Garg SK, Kelly WC, Voelmle MK, et al., Continuous home monitoring of glucose: improved glycemic control with reallife use of continuous glucose sensors in adult subjects with type 1 diabetes, Diabetes Care, 2007;30(12):3023-5

35. Chase HP, Beck RW, Xing D, et al., Continuous glucose monitoring in youth with type 1 diabetes: 12-month follow-up of the Juvenile Diabetes Research Foundation continuous glucose monitoring randomized trial, Diabetes Technol Ther, 2010;12(7):507-15

36. Ludvigsson J, Hanas R, Continuous subcutaneous glucose monitoring improved metabolic control in pediatric patients with type 1 diabetes: a controlled crossover study, Pediatrics, 2003;111(5 Pt 1):933-8.

37. De Block C, Manuel-y-Keenoy B, Van Gaal L, A review of current evidence with continuous glucose monitoring in patients with diabetes, I Diabetes Sci Technol, 2008;2(4):718-27.

38. Vazeou A, Continuous blood glucose monitoring in diabetes treatment, Diabetes Res Clin Pract, 2011;93 (Suppl.1):S125-30.

39. Harman-Boehm I, Continuous glucose monitoring in type 2 diabetes, Diabetes Res Clin Pract, 2008;82 (Suppl.2):S118-21.

40. Gandhi GY, Kovalaske M, Kudva Y, et al., Efficacy of continuous glucose monitoring in improving glycemic contro and reducing hypoglycemia: a systematic review and metaanalysis of randomized trials, I Diabetes sci Technol, 2011;5(4):952-65

41. Chase HP, Roberts MD, Wightman C, et al., Use of the Glucowatch biographer in children with type 1 diabetes, Pediatrics, 2003;111(4 Pt 1):790-4.

42. Chase HP, Beck R, Tamborlane W, et al., A randomized multicenter trial comparing the GlucoWatch Biographer with standard glucose monitoring in children with type 1 diabetes, Diabetes Care, 2005;28(5):1101-6.

43. Battelino T, Phillip M, Bratina N, et al., Effect of continuous glucose monitoring on hypoglycemia in type 1 diabetes, Diabetes Care, 2011;34(4):795-800

44. Deiss D, Hartmann R, Schmidt J, Kordonouri O, Results of a randomised controlled cross-over trial on the effect of continuous subcutaneous glucose monitoring (CGMS) on glycaemic control in children and adolescents with type diabetes, Exp Clin Endocrinol, Diabetes, 2006;114(2):63-7.

45. Lee SW, Sweeney T, Clausen D, et al., Combined insulin pump therapy with real-time continuous glucose monitoring significantly improves glycemic control compared to multiple daily injection therapy in pump naïve patients with type 1 diabetes; single center pilot study experience, I Diabetes Sci Technol, 2007;1(3):400-4.

46. Deiss D, Bolinder J, Riveline J-P, et al., Improved glycemic control in poorly controlled patients with type 1 diabetes using real-time continuous glucose monitoring, Diabetes Care, 2006;29(12):2730-2.

47. Cooke D, Hurel SJ, Casbard A, et al., Randomized controlled trial to assess the impact of continuous glucose monitoring on $\mathrm{HbA}_{1} \mathrm{C}$ ) in insulin-treated diabetes (MITRE Study), Diabet Med, 2009:26(5):540-7.

48. Newman SP, Cooke D, Casbard A, et al., A randomised controlled trial to compare minimally invasive glucose monitoring devices with conventional monitoring in the management of insulin-treated diabetes mellitus (MITRE) Health Technol Assess, 2009;13(28):iii-iv, ix-xi, 1-194.

49. O'Connell MA, Donath S, O'Neal DN, et al., Glycaemic impact of patient-led use of sensor-guided pump therapy in type 1 diabetes: a randomised controlled trial, Diabetologia, 2009:52(7):1250-7.

50. Raccah D, Sulmont $V$, Reznik $Y$, et al., Incremental value of continuous glucose monitoring when starting pump therapy in patients with poorly controlled type 1 diabetes: the RealTrend study, Diabetes Care, 2009;32(12):2245-50.

51. Meade LT, The use of continuous glucose monitoring in patients with type 2 diabetes, Diabetes Technol Ther, 2012;14(2):190-5.

52. Cosson E, Hamo-Tchatchouang E, Dufaitre-Patouraux L, et al., Multicentre, randomised, controlled study of the impact of continuous sub-cutaneous glucose monitoring (GlucoDay) on glycaemic control in type 1 and type 2 diabetes patients, Diabetes Metab, 2009;35(4):312-8.

53. Ehrhardt NM, Chellappa M, Walker MS, et al., The effect of real-time continuous glucose monitoring on glycemic control in patients with type 2 diabetes mellitus, I Diabetes Sci Technol, 2011;5(3):668-75

54. Yoo HJ, An HG, Park SY, et al., Use of a real time continuous glucose monitoring system as a motivational device for poorly controlled type 2 diabetes, Diabetes Res Clin Pract, 2008;82(1):73-9.

55. Allen NA, Fain JA, Braun B, Chipkin SR, continuous glucose monitoring counseling improves physical activity behaviors of individuals with type 2 diabetes: a randomized clinical trial, Diabetes Res Clin Pract, 2008;80(3):371-9.

56. Riddell $\mathrm{M}$, Perkins BA, Exercise and glucose metabolism in persons with diabetes mellitus: perspectives on the role for continuous glucose monitoring, I Diabetes Sci Technol, 2009:3(4):914-23.

57. Hay LC, Wilmshurst EG, Fulcher G, Unrecognized hypo- and hyperglycemia in well-controlled patients with type 2 diabetes mellitus: the results of continuous glucose monitoring, Diabetes Technol Ther, 2003;5(1):19-26.

58. Klupa T, Malecki MT, Sieradzki J, The continuous glucose monitoring system is effective in determining major factors affecting postprandial glycemic patterns in people with type 2 diabetes, J Diabetes Sci Technol, 2008;2(3):541-2.

59. Ceriello A, The post-prandial state and cardiovascular disease: relevance to diabetes mellitus, Diabetes Metab Res Rev 2000;16(2):125-32.

60. Ramchandani N, Arya S, Ten S, Bhandari S, Real-life utilization of real-time continuous glucose monitoring: the complete picture, I Diabetes Sci Technol, 2011;5(4):860-70.

61. Mitka M, Monitoring glycemic control in diabetes: new standardized reference measure a useful tool, JAMA, 2007;298(19):2252.

62. Joseph J, Effects of implantation on glucose sensor performance, Presented at: Diabetes Technology Meeting, San Francisco, 2011.

63. Klueh U, Liu Z, Feldman B, et al. Metabolic biofouling of glucose sensors in vivo: role of tissue microhemorrhages, J Diabetes Sci Technol, 2011;5(3):583-95.

64. Ward KW, A review of the foreign-body response to subcutaneously-implanted devices: the role of macrophages and cytokines in biofouling and fibrosis, I Diabetes Sci Technol, 2008;2(5):768-77

65. Draft Guidance for Industry and Food and Drug Administration Staff: The Content of Investigational Device Exemption (IDE) and Premarket Approval (PMA) Applications for Low Glucose Suspend (LGS) Device Systems. 2011.

66. Guardian $®$ REAL-Time and Paradigm $®$ REAL-Time systems P980022/S015. Available at: http://www.accessdata.fda.gov/cdrh_docs/pdf/ P980022S015c.pdf

67. STS-7 continuous glucose monitoring system P050012/S001. Available at: http://www.accessdata.fda.gov/cdrh_docs/pdf5/ P050012S001c.pdf

68. FreeStyle Navigator ${ }^{\circledR}$ continuous glucose monitoring system - P050020. Available at: http://www.accessdata.fda.gov/cdrh_docs/pdf5/P050020c.pd

69. Ginsberg BH, The current environment of CGM technologies, J Diabetes Sci Technol, 2007;1(1):117-21.

70. Kovatchev B, Anderson S, Heinemann L, Clarke W, Comparison of the numerical and clinical accuracy of four continuous glucose monitors, Diabetes Care, 2008;31(6):1160-4.

71. Kuo C-Y, Hsu C-T, Ho C-S, et al., Accuracy and precision evaluation of seven self-monitoring blood glucose systems, Diabetes Technol Ther, 2011;13(5):596-600.

72. Orsense, Inc. clinical trials - blood glucose monitoring Available at: http://www.orsense. $\mathrm{com} /$ ? id=815 (accessed 12 September 2011)

73. Valgimigli F, Lucarelli F, Scuffi C, et al., Evaluating the clinical accuracy of GlucoMen®Day: a novel microdialysis-based continuous glucose monitor, J Diabetes Sci Technol, 2010;4(5):1182-92.

74. Mayzel Y, Gal A, Harman-Boehm I, et al., Evaluation of performance and efficacy of GlucoTrack $B$, a truly non-invasive glucose monitor for home-use. Available at: glucose monitor for home-use. Available a
http://www.integrity-app.com/brochures/ Poster\%202\%20Final\%20Sep\%202011.pdf (accessed 12 Sester\%202\%20Fin. 